\title{
Redesain Museum Jawa Tengah Ronggowarsito Di Kota Semarang Dengan Pendekatan Pengalaman Ruang
}

\author{
Amalia Devitasari, Rachmadi Nugroho, Ahmad Farkhan \\ Program Studi Arsitektur \\ Fakultas Teknik \\ Universitas Sebelas Maret Surakarta \\ Email : adevi812@gmail.com
}

\begin{abstract}
The Redesign of Museum Central Java Ronggowarsito is motivated by implementation mismatches of its vision and mission to increase the appreciation of culture, raise awareness of the community, providing a source of cultural learning fun, provide excellent service, and being a pride for Central Java. The mismatch is accompanied by the low response and lack of enthusiasm of Semarang residents to visit the appreciation place of cultural heritage. The number of visitors doesn't significantly rise throughout the last 20 years. Design issues are important aspects in improving visitor attraction, the provision of services in aspects of visual and spatial experience that can not be conveyed properly to visitors at the Museum of Central Java Ronggowarsito. The Redesign method is POE (Post Occupancy Evaluation) on the conditions and elements of the existing museum, with a redesign strategy that emphasizes the concept of sequence and flow of visitors in the museum. The concept of zoning is key points in the implementation of the space experience in setting based on three major themes, in order to facilitate the visitors in the museum complex reading program. The space experience approach is chosen to support the process of appreciation of culture with fun and interesting way in accordance to the vision and mission of the museum, so it can be community's pride and become a major historical tourist destination of the Central Java which said in RKPD Semarang City 2015. The space experience approach also aims to support interaction among the visitors to the museum and its collection.
\end{abstract}

Keywords: Appreciation, Attraction, Flow, Support Interaction, Museum, Spatial Experience, Sequence, Redesign, Vission and Mission.

\section{PENDAHULUAN}

Semarang sebagai Ibukota Jawa Tengah telah memiliki wadah apresiasi warisan budaya yaitu Museum Jawa Tengah Ronggowarsito. Keberadaan wadah budaya tersebut belum diiringi dengan tingginya respon dan antusiasme warga Semarang. Terbukti jumlah pengunjung yang tidak mengalami kenaikan cukup spesifik sepanjang 20 tahun terakhir. Fenomena tersebut juga belum sejalan dengan visi dan misi Museum Jawa Tengah Ronggowarsito untuk meningkatkan apresiasi budaya, meningkatkan kepedulian masyarakat, penyediaan sumber belajar budaya yang menyenangkan, memberikan pelayanan prima, dan menjadi museum kebanggaan masyarakat Jawa Tengah.

Berdasarkan ICOM (International Council of Museum) 2004, aspek yang penting untuk diperhatikan dalam upaya meningkatkan daya tarik pengunjung adalah penyediaan servis dalam aspek penglihatan dan Pengalaman Ruang. Setelah melakukan kajian evaluasi eksisting dengan melakukan studi observasi secara langsung ke museum, kedua aspek tersebut belum dapat tersampaikan dengan baik kepada pengunjung di Museum Jawa Tengah Ronggowarsito.

Perancangan redesain Museum Jawa Tengah Ronggowarsito dengan pendekatan Pengalaman Ruang, diharapkan dapat menjadi sumbangan pemikiran dan gagasan yang menjawab visi dan misi Museum Jawa Tengah Ronggowarsito, serta menunjang terjadinya proses interaksi dialog antara pengunjung dengan museum.

Pendekatan Pengalaman Ruang dipilih guna menunjang terjadinya proses apresiasi budaya yang menyenangkan dan menarik sesuai dengan visi dan misi museum, sehingga dapat menjadi kebanggaan masyarakat serta menjadi tujuan utama wisata sejarah Jawa 
Tengah sesuai RKPD Kota Semarang Tahun 2015.

\section{METODE}

Metode perancanagan redesain dimulai dengan mengumpulkan datadata yakni data terkait proses perancangan redesain seperti data lokasi eksisting, data jumlah pengunjung, dan data jenis koleksi Museum Jawa Tengah Ronggowarsito. Selain itu juga terdapat tinjauan pustaka terkait teori redesain, teori POE (Post Occupancy Evaluation), pedoman museum di Indonesia, teori Pengalaman Ruang, dan preseden museum dengan penerapan Pengalaman ruang. Seluruh data didapat melalui studi observasi, dokumentasi, studi literatur, dan studi komparasi.

Analisis perencanaan (building concept) dilakukan dengan mengidentifikasi hasil evaluasi umum dan khusus dari proses $P O E$ eksisting Museum Jawa Tengah Ronggowarsito, sebagai pedoman arah perencanaan dan memberikan manfaat perencanaan dalam mencapai tujuan dan sasaran perancangan redesain museum.

Analisis perancangan (building criteria) dilakukan dengan mengolah data yang telah terkumpul dan dikelompokkan berdasarkan pemograman fungsional, performasi, dan arsitektural.

1. Pemrograman fungsional bertujuan untuk mengidentifikasi kegiatan yang diwadahi berupa pelaku kegiatan, bentuk kegiatan dan pola kegiatan, serta redesain museum yang direncanakan meliputi fasilitas museum dan penerapan pengalaman ruang pada susunan sequence ruang pamer.

2. Pemrograman performasi menerjemahkan secara sistematik kebutuhan para pengunjung museum berserta fasilitasnya ke dalam persyaratan ruang pamer, persyaratan besaran ruang, dan program kegiatan di dalam museum yang diredesain.

3. Analisis arsitektural merupakan tahap penggabungan dari hasil identifikasi kedua analisa sebelumnya (fungsional dan performasi). Dalam proses ini akan menganalisa konsep peruangan, konsep pengolahan tapak, konsep pengolahan ruang, konsep pemilihan material, konsep struktur serta utilitas.

\section{ANALISIS}

A. Analisis Peruangan dan Pemintakatan

1. Pelaku kegiatan Pelaku kegiatan terdiri dari:

a. Pengunjung museum.

b. Pengelola museum.

2. Analisis peruangan secara umum mengikuti kegiatan eksisting museum dengan penyempurnaan pada bentuk kegiatan pameran dan penunjang.

3. Pemintakatan pada redesain Museum Jawa Tengah

Ronggowarsito

Dasar pertimbangan:

a. Macam sifat pemintakatan museum.

b. Karakter kegiatan di Museum Jawa Tengah Ronggowarsito.

c. Hubungan antar fasilitas museum.

d. Pola sirkulasi pelaku kegiatan Museum Jawa Tengah Ronggowarsito.

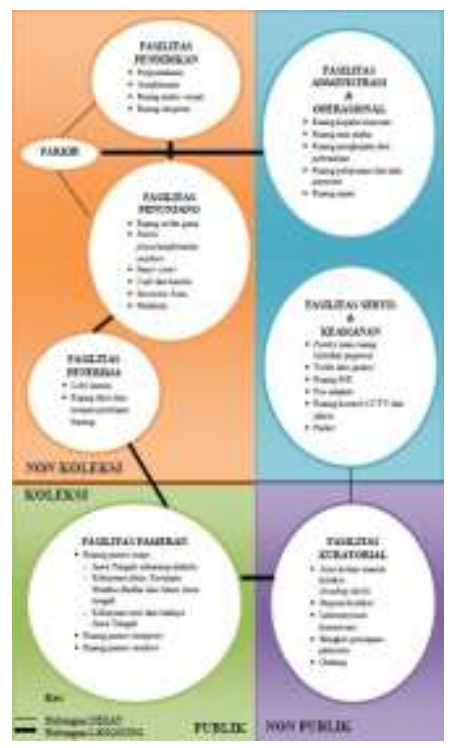

Gambar 1. Skema Pemintakatan dan Hubungan Fasilitas Museum Jawa Tengah Ronggowarsito 
4. Proses analisis: peruangan dan pemintakatan dalam redesain Museum Jawa Tengah Ronggowarsito, memperhatikan hubungan antar fasilitas museum dengan eksistensi ruang pamer sebagai fasilitas utama museum (Gambar 1).

B. Analisis Eksisting Lokasi

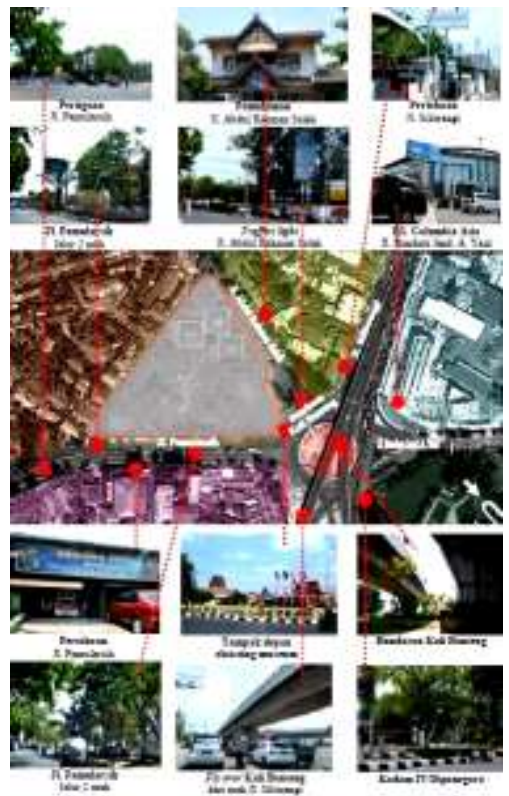

Gambar 2. Kondisi Sekitar pada Eksisting Lokasi Museum Jawa Tengah Ronggowarsito

Eksisting lokasi Museum Jawa Tengah Ronggowarsito cukup strategis sebagai potensi untuk mengekspos penampilan museum. Lokasi berada di pertemuan pertigaan flyover Kali Banteng Semarang, yaitu antara Jl. Abdul Rahman Saleh dan Jl. Pamularsih dengan bentuk tapak segitiga. Analisis eksisting lokasi mempertimbangkan focal point museum agar mengarah pada bundaran Kali Banteng (Gambar 2).

C. Analisis Pencapaian

1. Tujuan: menentukan pencapaian ke dalam museum yang mudah diakses, mudah dilihat, dan memiliki sirkulasi yang aman dalam menstimulus pengunjung untuk masuk ke dalam area museum, serta kegiatan pengelola maupun loading koleksi museum.

2. Hasill: pencapaian utama in/out ke dalam/keluar area museum sebagai Main Entance berada di Jl. Abdul Rahman Saleh. Side Entance berada di Jl. Pamularsih sebagai akses in/out pengelola dan loading koleksi museum (Gambar 3).

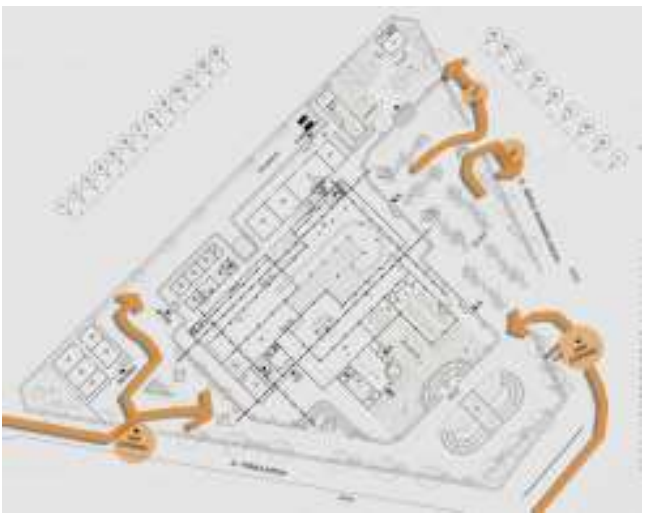

Gambar 3. Pola Pencapaian

D. Analisis Tatanan Massa

1. Tujuan: menentukan tatanan massa berdasarkan flow pengunjung di dalam area museum

2. Dasar pertimbangan:

a. Makna khusus atau keterkaitan dengan materi koleksi.

b. Focal point penampilan museum.

c. Interaksi dialog antara bangunan museum dengan pengunjung.

d. Bentuk sirkulasi bagi pengunjung untuk merasakan pengalaman ruang.

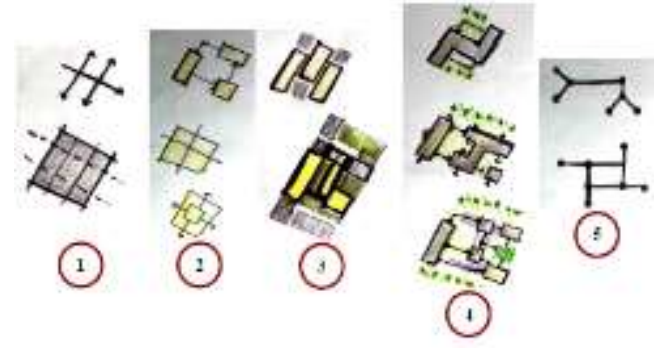

Gambar 4. Analisis Tatanan Massa

3. Proses analisis: tatanan massa dibuat dengan mengubah arah as, mengarah pada bundaran Kali Banteng di sisi utara. Tatanan 
massa memperhatikan bentuk sirkulasi yang memiliki makna khusus untuk menciptakan susunan suasana di dalam area ruang pamer museum (Gambar 4).

4. Hasil: tatanan massa menunjang terjadinya interaksi dialog antara konsep alur cerita pada sequence ruang pamer yang memiki 3 tema besar dengan flow pengunjung di dalam area museum (Gambar 5).

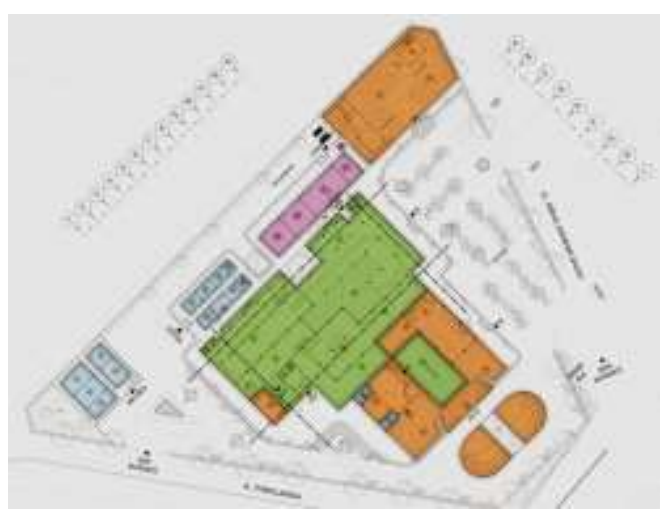

Gambar 5. Tatanan Massa pada Layout Site Plan Redesain Mueum Jawa Tengah Ronggowarsito

E. Analisis Pengolahan Ruang

1. Tujuan: menentukan pengolahan ruang khususnya di dalam area ruang pamer yang memiliki mekanisme sebagai penyalur ekspresi ruang dan memberikan kepuasan estetika visual.

2. Dasar pertimbangan:

a. Elemen pembentuk ruang, kualitas ruang, rangkaian skala ruang, perhubungan ruang demi ruang mengadopsi dari Edward, T.White (2000), terjemahan Buku Sumber Konsep sebuah kosa-kata bentuk-bentuk arsitektural.

b. Kemudahan sirkulasi yang dicapai secara merata tanpa jenuh dan lelah.

c. Sistem penyajian koleksi pada ruang pamer.

d. Susunan suasana pada sequence ruang pamer.

3. Proses Analisis: pengolahan ruang sebagai sasaran utama redesain, memperlihatkan potensi koleksi museum sebagai penyalur ekspresi ruang. Konsep sequence di setting mampu menggerakkan emosi pengunjung. Skala dan proporsi ruang dibuat untuk menekankan keintiman ruang atau memberikan rasa lega. Secara garis besar ruang pamer tetap terbagi menjadi 3 tema besar yang menjadi bahan setting Pengalaman Ruang museum yaitu:
a. Jawa Tengah sekarang dan dahulu.
b. Kerajaan Hindhu, Budha, dan Islam di Jawa Tengah.
c. Kekayaan seni dan budaya Jawa Tengah. (Gambar 6)

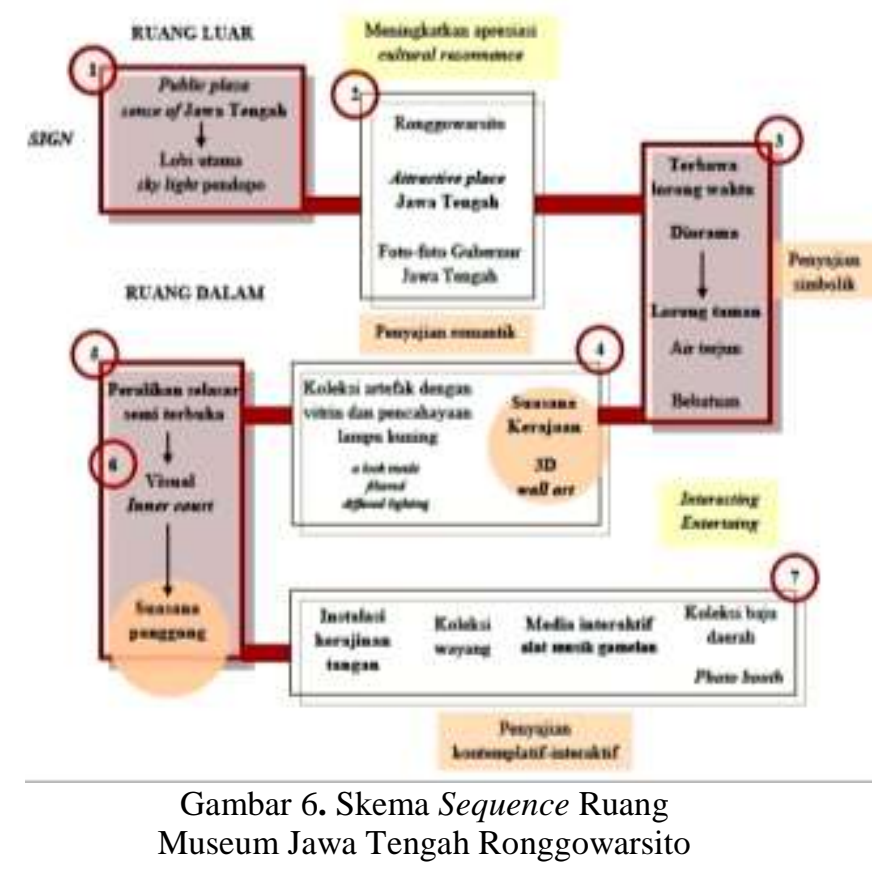

4. Hasil: setting alur cerita dimulai sejak awal pengunjung memasuki area museum. Area main entrance museum memiliki sifat keterbukaan yang mengingatkan pengunjung akan alunalun sebagai tempat berkumpul. Disetiap ruang pamer di setting dengan beberapa metode penyajian untuk meningkatkan cultural ressonance pengunjung. Setiap peralihan menuju ruang pamer berikutnya selalu memiliki makna khusus. Terdapat inner court di dalam area ruang pamer museum sebagai area semi outdoor 
sekaligus sebagai reward view (Gambar 7).

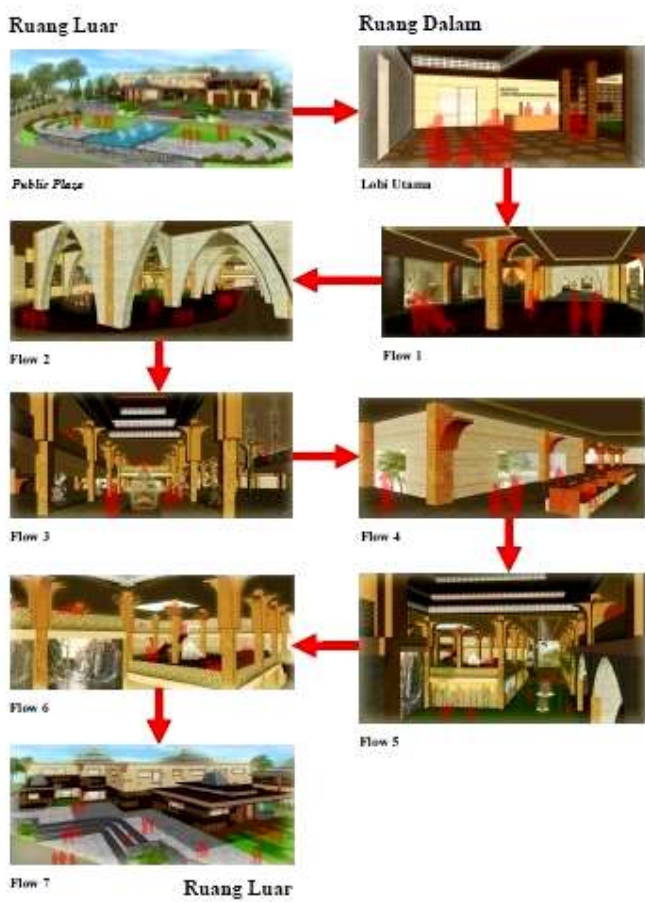

Gambar 7. Pengolahan Ruang dengan Konsep Sequence di Museum Jawa Tengah Ronggowarsito

F. Analisis Penampilan Bangunan

1. Tujuan: mendapatkan penampilan museum yang estetis dan memberikan kesegaran baru pada wajah museum.

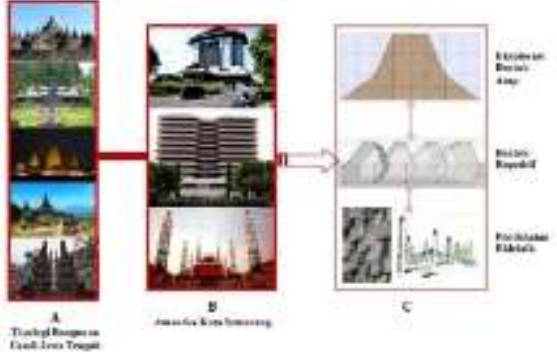

Gambar 8. Analisa Penampilan Museum Jawa Tengah Ronggowarsito

2. Dasar pertimbangan:

a. Mempertahankan ciri khas aksen Jawa Tengah.

b. Penyegaran penampilan museum yang kontekstual.

c. Menguntungkan penampilan museum yang bisa berbeda dari ketiga sisi, berdasar bentuk tapak yang unik yaitu berupa segitiga.

(Gambar 8)

3. Proses analisis: penampilan museum memperhatikan tipologitipologi bangunan candi dan bangunan attractive di Kota Semarang sebagai unsur regionalis. Penampilan museum juga mengkombinasikan unsur-unsur modern dan eksplorasi material sesuai dengan penyesuaian kebutuhan museum. Penampilan bangunan secara khusus mengambil bentuk atap Joglo sebagai konsep bentuk eksplorasi atap pada museum baru. Bentukbentuk repetitif atau pola berirama menjadi perhatian dalam menyajikan penampilan museum yang estetis dan menarik dari ketiga sisi. Komponen-komponen desain direncanakan dengan pendekatan eklektik yang menggabungkan karakter tradisional dan modern (Gambar 9).

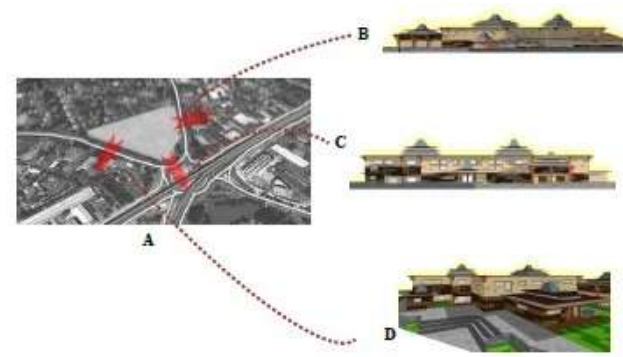

Gambar 9. Bentuk Tapak yang Berupa Segitiga Menguntungkan Penampilan Museum Jawa Tengah Ronggowarsito

G. Analisis Struktur

1. Tujuan: mendapatkan sistem struktur yang sesuai dengan pembebanan.

2. Dasar pertimbangan:

a. Jarak/bentang kolom terhadap penataan koleksi.

b. Beban koleksi museum.

c. Adanya skylight yang mengadopsi bentuk tumpang sari, jika di lihat pengunjung dari dalam ruang pamer. 


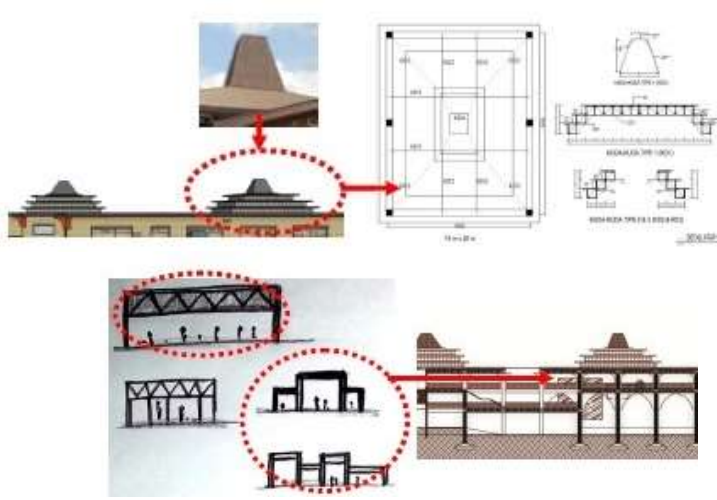

Gambar 10. Struktur Atap Portal Baja dan Beton Bertulang di Museum Jawa Tengah Ronggowarsito

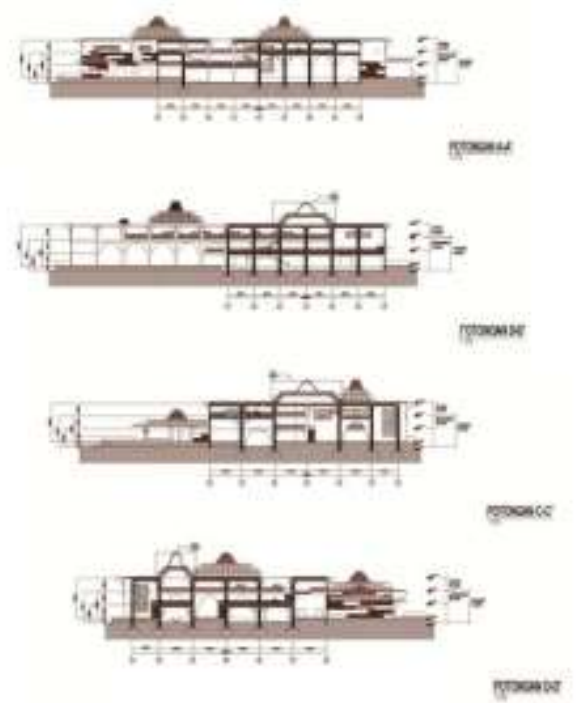

Gambar 11. Sistem Struktur di Museum Jawa Tengah Ronggowarsito

3. Proses analisis: aplikasi struktur atap yang mengadopsi bentuk atap Joglo dengan penyesuaian struktur yang lebih modern, menjadi sasaran utama perancangan struktur redesain museum. Secara umum struktur yang digunakan dalam bangunan adalah perpaduan dari struktur atap portal baja dan beton bertulang, dengan jarak/bentang kolom adalah $8 \quad \mathrm{~m} \quad \mathrm{x} \quad 10 \mathrm{~m}$. Beberapa bagian menggunakan struktur beton bertulang dipadu dengan sistem portal baja dengan pertimbangan beban bangunan dan kenyamanan ruang (Gambar 10, Gambar 11).

\section{KESIMPULAN (KONSEP DESAIN)}

Konsep perencanaan dan perancangan redesain Museum Jawa Tengah Ronggowarsito mengacu pada konsep desain dengan pendekatan Pengalaman Ruang, khususnya diterapkan pada konsep pengolahan ruang. Pengolahan ruang sebagai sasaran utama redesain, memperlihatkan potensi koleksi museum sebagai penyalur ekspresi ruang yang memberikan kepuasan visual (Gambar 12,13). Konsep sequence di setting mampu menggerakkan emosi pengunjung. Skala dan proporsi ruang dibuat untuk menekankan keintiman ruang atau memberikan rasa lega. Bentuk sirkulasi dibuat agar dapat merasakan Pengalaman Ruang, serta mudah dicapai secara merata tanpa jenuh dan lelah (Gambar 14). Hal tersebuat bertujuan menunjang terjadinya interaksi dialog antara bangunan museum dengan pengunjung yang menyenangkan dan menarik, sesuai visi dan misi museum (Gambar 15).

Dari hasil analisa serta hasil korelasi dari beberapa data di atas, maka diperoleh hasil berupa rancangan sebagai berikut:

Nama Museum : Museum Jawa Tengah Ronggowarsito

Lokasi : Jl. Abdul Rahman Saleh

Luas Lahan : $28.000 \mathrm{~m}^{2}$

Luas Bangunan : $10.077 \mathrm{~m}^{2}$

Daya Tampung : 1.380 orang

Kegiatan : Apresiasi budaya dan edutaiment

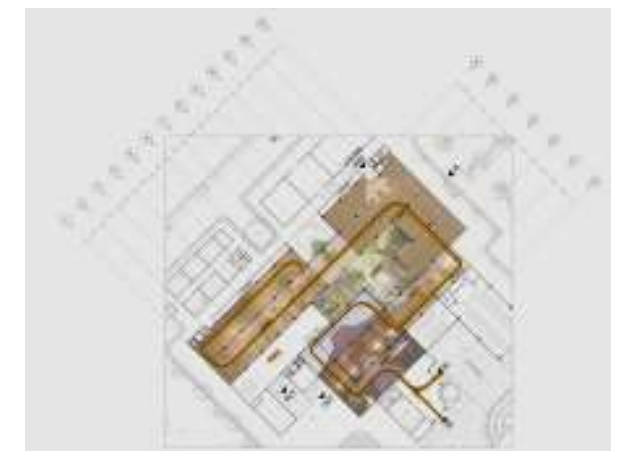

Gambar 12. Layout Ground Floor Museum Jawa Tengah Ronggowarsito 


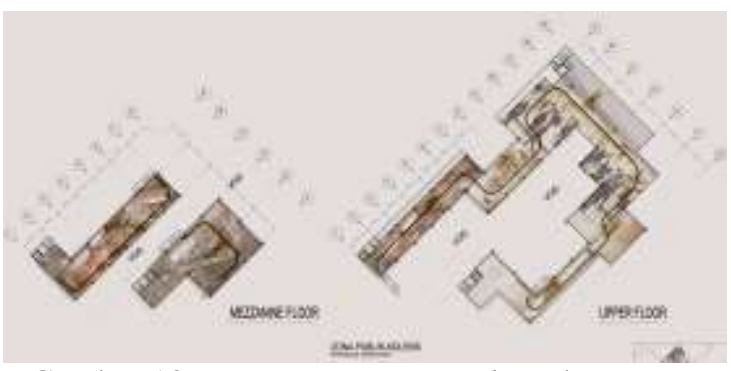

Gambar 13. Layout Mezzanine Floor dan Upper

Floor Museum Jawa Tengah Ronggowarsito

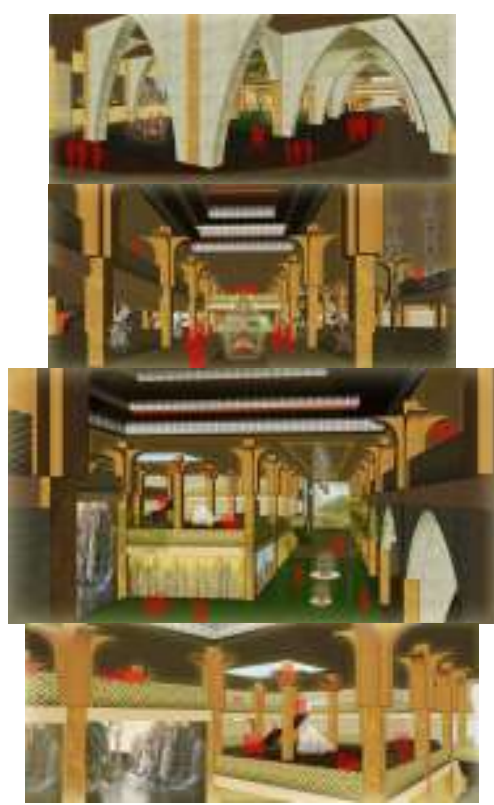

Gambar 14. Interior Museum Jawa Tengah Ronggowarsito

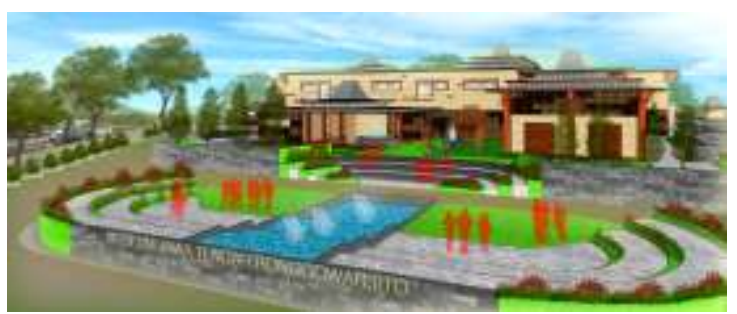

Gambar 15. Eksterior Museum Jawa Tengah Ronggowarsito

\section{REFERENSI}

Direktorat Permuseuman. Pedoman

Museum Indonesia. Jakarta: Direktorat Pelestarian Cagar Budaya dan Permuseuman, 2012.

T. White, Edward. Buku Sumber Konsep sebuah kosa-kata bentuk-bentuk arsitektural. Bandung: Kotak Pos 4848, 2000.

ICOM Code Ethics for Museums. 2013 